\title{
MEMORY STUDIES IN ELECTRIC CONVULSION THERAPY
}

\author{
BY \\ MOYRA WILLIAMS \\ From the Research Department, Graylingwell Hospital, Chichester
}

The disturbances of memory immediately following electric convulsion therapy (E.C.T.) have been the subject of many investigations (Zubin and Barrera, 1941 ; Mayer-Gross, 1943 ; Liberson and Wilcox, 1945 ; Kalinowsky and Hoch, 1947). Implicit, if not explicit, in the majority of these papers is the assumption that memory can be studied in isolation. Bartlett, however, (1932), long ago demonstrated that what a person remembers depends on many other factors within the fields of personality and mental activity, and Stone (1947 $a$ and $b$ ), studying the effect of E.C.T. on mental activity in general, found that memory was not the only mental function to suffer temporary impairment from this form of treatment. Wittman and Russell (1942) also noted that mental efficiency and memory levels following other forms of shock therapy were directly correlated - with changes in the patient's general attitude, while much of the German literature stresses the presence of disturbances in other spheres of mental activity as well as that of memory in the Korsakoff states to which post-E.C.T. amnesias are allied.

In view of these reports it seems desirable that some studies of the memory changes following E.C.T. should be combined with studies of other mental functions, the most frequently disturbed of which in the organic amnesic state appears to be that of perception (Bonhoeffer, 1901 ; Bumke, 1928 ; MacCurdy, 1928 ; Bürger-Prinz and Kaila, 1930). Since Löwenbach and Stainbrook (1942) also found temporary modifications in the responses to the Rorschach test in the records of post-E.C.T. patients, it seemed likely that a useful preliminary investigation would be one in which perceptual changes were taken into account at the same time as the memory defects were measured. This paper is an account of such a study. In order to allow for the assessment of perceptual disturbances, material of an ill-defined and ambiguous nature has been used of a type somewhat similar to that in the Rorschach test and in contrast to the well defined words or pictures reported on by the majority of other workers.

\section{Method}

Test Material.-The material used in the investigation consisted of four sets of nine pictures each. The first picture in each set was a nearly circular ink blot, and the last in each set a fairly representative silhouette study of an animal (cat, elephant, rabbit, and goose), while the intervening pictures showed various stages between the two extremes. Each set was graded so that those nearest the beginning of the set were least like the final product while those nearest the end were most like it.

Administration.-Before beginning the test, the subjects were instructed as follows (the actual words were not strictly adhered to, so long as the gist was made clear to each subject) :

"I have here a picture, which, as you see, is just like an ink blot. But as I turn over the pages, this ink blot will begin to look more and more like an animal. I want you to tell me as soon as you can what sort of animal you think it is going to finish by representing. Can you make a guess straight away now ?"

All verbal responses by the subjects were noted. If the name of an animal was volunteered, the experimenter replied, " That's not a bad guess," and turning over the page, "What about it now?" If no animal's name was

TABle I

ANALYSIS OF AVERAGE STAGE OF RECOGNITION OF FOUR SETS OF PICTURES

\begin{tabular}{|c|c|c|c|c|}
\hline $\begin{array}{c}\text { Point of } \\
\text { Recognition }\end{array}$ & Cat & Elephant & Goose & Rabbit \\
\hline $\begin{array}{c}\text { Not recog- } \\
\text { nized* } \\
9 \\
8 \\
7 \\
6 \\
5 \\
4 \\
3 \\
2 \\
1\end{array}$ & $\begin{array}{c}2 \\
\dddot{1} \\
3 \\
4 \\
3 \\
\dddot{1} \\
1 \\
\cdots\end{array}$ & $\begin{array}{c}\cdots \\
2 \\
5 \\
4 \\
2 \\
1 \\
\cdots \\
\cdots \\
\cdots\end{array}$ & $\begin{array}{c}\cdots \\
\ddot{1} \\
6 \\
5 \\
3 \\
1 \\
\cdots \\
\cdots\end{array}$ & $\begin{array}{c}2 \\
1 \\
5 \\
4 \\
5 \\
2 \\
\cdots \\
\cdots \\
\cdots\end{array}$ \\
\hline $\mathbf{N}$ & 15 & 14 & 16 & 19 \\
\hline Mean & $6 \cdot 2$ & $6 \cdot 3$ & $6 \cdot 2$ & $7 \cdot 2$ \\
\hline
\end{tabular}

* Counted as Stage 10 and credited 10 points. 
given and the patient merely described the blot as "looking like a potato," or " nothing at all," the page was again turned, and the question, "What about it now ?" repeated.

No time limit was set for a response, and the subjects were never hurried or prompted. If their attention seemed to have wandered, they were brought back to the task by a repetition of the question, "What does this look like?" or, "What animal do you think this will turn into?" and the page was never turned until the patient had either responded to a picture by giving it a name or signified that he was unable to do so.

The number of the picture which first elicited mention of the correct animal was scored as the "point of recognition," even when this was obviously a guess, or when at later pictures the subject changed his mind. Thus, on the elephant set, a patient might respond to No. 3 by saying, "I think it's going to be an elephant," and to No. 4 by saying, " Now it looks more like a bear," nevertheless, his point of recognition was taken as Stage 3.

Preliminary Standardization.-Before the experiment itself was begun, the sets of pictures were shown to a number of patients and staff in the hospital in order to ascertain their comparability. Each individual was shown two of the sets, the points of recognition on each being noted. Standardization was not carried out on a. strictly statistical basis, but from the distribution of the points of recognition shown for the four sets in Table I it will be seen that three of the sets, cat, elephant, and goose, are recognized on the average at about the same stage. As the rabbit was recognized on the average rather later than the others, it was discarded and was not used in the main experiment.

A second preliminary investigation was made in order to ascertain whether recognition on the first set helped or impeded recognition on the second set. Table II shows the difference in the points of recognition for the cat and elephant presented alternately first and second to 41 subjects.

TABLE II

DIFFERENCE IN POINTS OF RECOGNITION OF CAT AND ELEPHANT

\begin{tabular}{c|c}
\hline $\begin{array}{c}\text { Difference in Points of } \\
\text { Recognition }\end{array}$ & No. of Subjects \\
\hline First-Second & \\
\hline+3 & 4 \\
+2 & 3 \\
+1 & 4 \\
0 & 8 \\
-1 & 10 \\
-2 & 11 \\
-3 & 1 \\
\hline Mean Difference $-\cdot 32$ & \\
\hline
\end{tabular}

It will be seen that there is a slight tendency to recognize the second set earlier than the first, but that the difference is almost insignificant.
Subjects.-The subjects for the main experiment were male and female patients at Graylingwell Hospital who were undergoing electric-shock therapy. No form of selection was used in choosing subjects, except that all had to be capable of recognizing and correctly naming simple pictures. Some of these patients had been in hospital for many years ; others were recent admissions. Some were seen before and after their first shock, others while in the middle of a course of treatment, and still others after occasional treatment for management purposes. Some patients were extremely cooperative, while others were hostile and evasive and could only with difficulty be persuaded to take part in the test.

Despite the realization that different forms of administering shock therapy have different effects on retrograde amnesia (Liberson and Wilcox, 1945), the post-convulsive testing in this experiment was carried out after treatment had been given by several different methods, and after different quantities of dosage. In fact, the only factor kept constant was the state of consciousness at which the post-convulsive testing was begun.

Experimental Procedure.-The pictures were shown to the subjects at three different times or stages.

Stage 1 is the period before treatment. The time elapsing between presentation of the pictures and the beginning of treatment was not kept constant, and varied from a few seconds to several hours.

Stage 2 is the period immediately after treatment, while the subjects were still confused and amnesic. As soon as a patient was able to count correctly the number of fingers held up in front of him, and name simple objects such as a key, a pen, and a watch, he was shown the first set of pictures. At this time he was, of course, still unable to say where he was or to recognize the experimenter, both of which questions were asked as a routine. He was also asked as a routine question whether he had ever seen the pictures before, and invariably denied having done so.

Stage 3 is the period some hours after treatment, but before any further treatment. If treatment was given early in the morning, the next set of pictures was shown late that evening, while if treatment was given in the evening the next set of pictures was shown the following morning. At this time the patients were always well orientated again, and could usually remember having seen the experimenter and the set of pictures in Stage 1, but not in Stage 2.

It should be noted that the stages represent uniformity of consciousness, not of time interval. Thus even Stage 2 varied as regards its time after the beginning of treatment, some subjects being in a condition to cooperate very much sooner than others.

Procedure of Testing.--In Stage 1 the subject was shown one set of pictures only. Since the sets were taken in turn so as to overcome any possible differences in recognizability between them, the set shown at this time will be referred to as set $A$. In Stage 2, the subjects were shown set $A$ again $\left(A^{1}\right)$ and another set which will be referred to as set $B$. Although the patients at this time were able to obey simple instructions and answer simple 
questions, they were not able to understand complicated explanations. It was, therefore, impossible to make them realize that they were guessing what the pictures would become, so as each picture was held up in front of him the patient was simply asked, "What animal does this look like ?" or, "What animal is it most like?" It is important to realize that forecast guessing in Stage 2 was thus eliminated.

Since during every minute which elapses after treatment the subject's orientation, cognizance, and memory for past events improves, it is clear that whichever set of pictures is shown second in Stage 2 has the advantage of being perceived by a clearer mind. As against this, however, there is a tendency for responses made in the early post-convulsive period to perseverate. Thus, the response made to the first set of pictures seen in Stage 2 might, and was occasionally found to, perseverate and cause faulty responses to the second set. To eliminate the effects of either of these factors on the point of recognition on the two sets $A^{1}$ and $B$, these sets were alternately presented first and second at this stage.

As soon as set B had been run through and recognized, (or if it was presented before $\mathbf{A}^{\mathbf{1}}$, after the recognition of this set) it was presented again from the beginning (as $\mathbf{B}^{1}$ ) and its point of recognition determined for a second time. It is important to realize that even when less than a minute had elapsed between these two presentations, the subjects always denied at the second presentation of $\mathbf{B}$ that they had ever seen the pictures before.

In Stage 3, subjects were shown set $\mathbf{B}$ again $\left(\mathbf{B}^{11}\right)$ and also set $\mathbf{C}$. At this time they nearly always remembered having seen both the experimenter in Stage 1 and set $A$ at that time, but neither the experimenter nor set $\mathbf{B}$ from Stage 2. The experimental procedure is as follows :

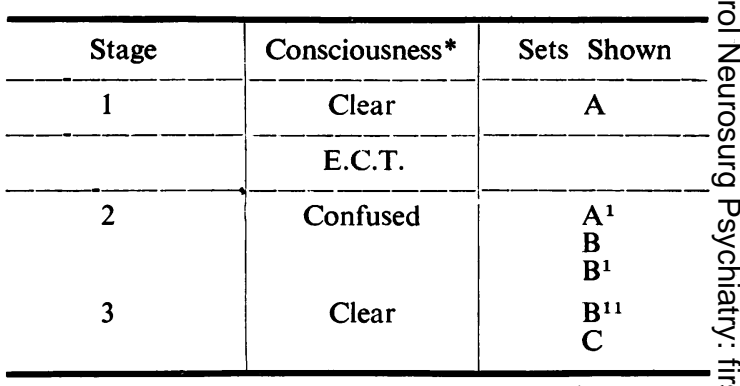

* Terms used in description here are only relative.

It should, however, be mentioned that for a variety of reasons not every patient was able to follow the complete 흐 procedure set out above. Thus, some patients saw $A \frac{\bar{S}}{T}$ and $A^{1}$; some $B, B^{1}, B^{11}$, and $C$. For this reason, the $\mathbb{\Phi}$ means in the following tables are not strictly comparable.

Results

The quantitative data are analysed under two headings :

\section{Effect of Preliminary Stimulation on Recognition in Confusional State}

Table III shows the points of recognition of set A $\vec{\omega}$ before treatment, of the same set $A^{1}$ after treatment $\vec{\omega}$ and of set $B$, which was seen for the first time afte treatment, for 19 subjects.

It will be noticed that whereas $A^{1}$ tends to recognized slightly earlier in the confusional state than it was before, the difference, however, being o small, B tends to be recognized much later after treatment than A was before treatment. Moreove

TABLE III

POINTS OF RECOGNITION FOR A BEFORE AND AFTER (A ${ }^{1}$ ) TREATMENT AND FOR B AFTER TREATMENT FOR 19 SUBJECTS

\begin{tabular}{|c|c|c|c|c|c|}
\hline \multicolumn{3}{|c|}{ Point of Recognition } & \multicolumn{3}{|c|}{ Difference between Points of Recognition } \\
\hline A & $\mathrm{A}^{1}$ & B & $\mathbf{A}-\mathbf{A}^{1}$ & A-B & $\mathbf{A}^{1}-\mathbf{B}$ \\
\hline $\begin{array}{l}6 \\
6 \\
6 \\
6 \\
6 \\
7 \\
3 \\
2 \\
7 \\
6 \\
5 \\
6 \\
7 \\
8 \\
4 \\
7 \\
6 \\
2 \\
8\end{array}$ & $\begin{array}{l}6 \\
4 \\
6 \\
8 \\
5 \\
3 \\
1 \\
3 \\
7 \\
5 \\
4 \\
6 \\
7 \\
8 \\
4 \\
4 \\
7 \\
3 \\
8\end{array}$ & $\begin{array}{r}7 \\
8 \\
6 \\
6 \\
10 \\
9 \\
79 \\
7 \\
5 \\
9 \\
6 \\
10 \\
8 \\
10 \\
6 \\
6 \\
69 \\
9 \\
7\end{array}$ & $\begin{array}{r}0 \\
-2 \\
0 \\
+2 \\
-1 \\
-4 \\
-2 \\
-1 \\
0 \\
-1 \\
-1 \\
0 \\
0 \\
0 \\
0 \\
\cdots \\
-1 \\
+1 \\
0\end{array}$ & $\begin{array}{r}+1 \\
+2 \\
0 \\
0 \\
+4 \\
+2 \\
\ddot{+} \\
+5 \\
+2 \\
+3 \\
+1 \\
+4 \\
+1 \\
+2 \\
+2 \\
+2 \\
\ddot{+} \\
+7 \\
-1\end{array}$ & $\begin{array}{r}+1 \\
+4 \\
0 \\
-2 \\
+5 \\
+6 \\
\ddot{+} \\
-2 \\
+4 \\
+2 \\
+4 \\
+1 \\
+2 \\
+2 \\
+2 \\
+2 \\
+6 \\
-1\end{array}$ \\
\hline & & $\mathrm{Me}$ & -.44 & +1.94 & $+2 \cdot 25$ \\
\hline
\end{tabular}


the familiar set of pictures, $A^{1}$, is in all except four cases recognized more easily than the unfamiliar set, the mean difference being $+2 \cdot 25$ stages. The difference between the points of recognition on these two sets, although both were seen at about the same time, indicates that the earlier recognition of the familiar set, $\mathbf{A}^{1}$, cannot be accounted for by a lessening of hostility or evasiveness on the part of the patient, since if this were the only factor influencing the patient's responses, it would affect recognition of both sets equally. When the plus and minus signs denoting the difference in points of recognition are arranged in a table of distribution (Table IV) and submitted to the $\chi^{2}$ test for goodness of fit in a $2 \times 2$ table, the value of $\chi^{2}$ is 9.8 , for which the probability that the differences could be due to chance is less than 0.002 (Fisher's table).

\section{Effect of Stimulation During Confusional Period on Later Recognition}

The effect of stimulation during the confusional periogd was investigated by repeated presentation of the pictures in set B immediately after the first presentation in Stage 2 when they are referred to as $\mathbf{B}^{1}$, and several hours later, when they are referred to as $\mathbf{B}^{11}$. Again it should be noted that at each presentation subjects denied having seen the set of pictures before. Table $\mathrm{V}$ shows the points of recognition for $B, B^{1}, B^{11}$, and $C$ for 15 patients. It will be noticed that the second time the set of pictures is presented during the confusional period it is usually recognized sooner than before. Although the time-interval between the first and second presentations of $B$ was never more than a few minutes, the second presentation was undoubtedly
TABLE IV

TABLE OF DISTRIBUTION OF DIFFERENCE IN POINTS OF RECOGNITION

\begin{tabular}{|c|c|c|}
\hline \multirow{2}{*}{$\begin{array}{l}\text { Difference in Points } \\
\text { of Recognition }\end{array}$} & $A-A^{1}$ & $A-B$ \\
\hline & $\begin{array}{l}\text { No. of } \\
\text { Subject }\end{array}$ & $\begin{array}{l}\text { No. of } \\
\text { Subject }\end{array}$ \\
\hline $\begin{array}{r}+7 \\
+6 \\
+5 \\
+4 \\
3 \\
2 \\
1 \\
0 \\
-1 \\
-2 \\
-3 \\
-4\end{array}$ & $\begin{array}{c}. . \\
. \\
. \\
\because \\
\dddot{1} \\
3 \\
8 \\
3 \\
2 \\
\dddot{1}\end{array}$ & $\begin{array}{c}1 \\
\dddot{1} \\
2 \\
1 \\
5 \\
3 \\
2 \\
1 \\
1 \\
\cdots \\
.\end{array}$ \\
\hline
\end{tabular}

experienced during a slightly clearer state of consciousness, which would be expected, from the results reported before, to assist in its recognition. However, the time-effect over such a short period does not appear to be very great. It will be remembered that in Stage 2, the sets $A^{1}$ and $B$ were shown with alternate ones first, so that one patient saw $A^{1}$ before $B$, and the next $B$ before $A^{1}$. If, for the total number of patients, the point of recognition on the set first seen is compared with that on the set seen second, it is possible to calculate the effect of time alone on the point of recognition, as the effects of familiarity and unfamiliarity will here cancel each other out. This has been done in Table VI and is compared with the difference in the points of recognition when the two sets of pictures are the same, $B$ and $B^{1}$. When the plus and minus values in

TABLE V

POINTS OF' RECOGNITION FOR B, $\mathbf{B}^{1}, \mathbf{B}^{11}$, AND C FOR 15 SUBJECTS

\begin{tabular}{|c|c|c|c|c|c|}
\hline \multicolumn{2}{|c|}{ Stage 2} & \multicolumn{2}{|c|}{ Stage 3} & \multicolumn{2}{|c|}{$\begin{array}{c}\text { Difference between Points of } \\
\text { Recognition }\end{array}$} \\
\hline B & $\mathbf{B}^{1}$ & $\mathbf{B}^{11}$ & C & B-B' & $\mathrm{B}^{11}-\mathrm{C}$ \\
\hline $\begin{array}{r}6 \\
6 \\
8 \\
9 \\
6 \\
7 \\
10 \\
7 \\
7 \\
7 \\
7 \\
7 \\
9 \\
8 \\
10\end{array}$ & $\begin{array}{r}4 \\
4 \\
7 \\
9 \\
1 \\
7 \\
10 \\
7 \\
6 \\
2 \\
3 \\
6 \\
7 \\
. \\
\end{array}$ & $\begin{array}{l}\cdots \\
\because 6 \\
8 \\
5 \\
4 \\
7 \\
6 \\
\cdots \\
6 \\
2 \\
6 \\
6 \\
7 \\
7\end{array}$ & $\begin{array}{l}\cdots \\
\because 5 \\
7 \\
4 \\
7 \\
4 \\
5 \\
\because \\
5 \\
7 \\
4 \\
2 \\
8 \\
5\end{array}$ & $\begin{array}{r}-2 \\
-2 \\
-1 \\
0 \\
-5 \\
0 \\
0 \\
0 \\
-1 \\
-5 \\
-4 \\
-1 \\
-2 \\
-. \\
-.\end{array}$ & $\begin{array}{l}\ddot{\cdots} \\
-1 \\
-1 \\
-1 \\
+3 \\
-3 \\
0 \\
\cdots 1 \\
+5 \\
-2 \\
-4 \\
+1 \\
-2\end{array}$ \\
\hline \multicolumn{4}{|c|}{ Mean } & $-1 \cdot 76$ & -.5 \\
\hline
\end{tabular}


TABLE VI

COMPARISON BETWEEN POINTS OF RECOGNITION OF TWO DIFFERENT SETS OF PICTURES AND THE SAME SET

\begin{tabular}{|c|c|c|}
\hline $\begin{array}{l}\text { Difference in } \\
\text { Points of } \\
\text { Recognition }\end{array}$ & Different Sets & Same Set \\
\hline $\begin{array}{r}+5 \\
+4 \\
+3 \\
+2 \\
+1 \\
0 \\
-1 \\
-2 \\
-3 \\
-4 \\
-5 \\
-6\end{array}$ & $\begin{array}{r}2 \\
0 \\
1 \\
2 \\
1 \\
1 \\
\ddot{5} \\
2 \\
1 \\
\ddot{1}\end{array}$ & $\begin{array}{l}\ldots \\
\ldots \\
\ldots \\
\ldots \\
\ddot{4} \\
2 \\
3 \\
\ddot{1} \\
2 \\
\ldots\end{array}$ \\
\hline
\end{tabular}

Table VI are subjected to the $\chi^{2}$ test in a $2 \times 2$ table, the value of $\chi^{2}$ is 3.9 , and the probability that the difference between the distributions is due to chance is 0.05 (Fisher's table). A comparison between the points of recognition of the familiar and unfamiliar sets of pictures in Stage 3 (Table V), however, indicates little difference between them except that the unfamiliar set tends to have a slight advantage and to be recognized before the familiar one. Why this should be so is difficult to say, unless the failure to recognize $B$ in Stage 2 has a slightly retarding effect on its recognition in Stage 3. The difference, however, is not great enough to warrant any speculative explanations.

As well as the above quantitative data, some interesting points were noted in the individual records. It was frequently found that unusual responses which were aroused in a patient at a certain point on one set of pictures were again aroused on re-presentation of the same set, but at an earlier point in the series. Thus the whole series of responses seems to be more or less reproduced, but in a condensed form and slipped back a stage. The following are some examples.

A female patient was interviewed during the confusional state. She was first shown the set of pictures which turned into an elephant, then the set turning into a duck or goose (either response counting as correct). She was then shown the elephant set a second time and finally the goose set a second time. The following are her responses to each picture.

No. of

\section{Elephant Set}

Picture

\section{First Response}

Second Response

1. Not like any animal. Not like any animal.

2.,,,,,,,,,, ,,

3. $\quad$ 4.

5. A polar bëar. ", Still a polar bear.

6. Not like any animal. I still think so.

7. An elephant. An elephant.
1. No animal.

2. Nothing.

3. Someone's private.

4. That's the same.

5. Yes.

6. Sea lion.

7. A duck.

The following day her responses to the elephant set were as follows :

1. Nothing.

2. Nothing.

3. Something like a polar bear.

4. Yes.

5. Yes still.

6. An elephant.

Thus, not only was the response "elephant" given $\stackrel{\mathbb{2}}{\circ}$ sooner at repeated presentations, but the " polar bear" iै response showed the same tendency, appearing first to $\vec{\circ}$ card 5 , the next time to card 4 , and the third time to card 3. On the goose set, both the correct response and the " private part" response were shifted back a step on second presentation.

A male patient was shown the elephant set before treatment and again in the confusional state after it. The following is a comparison of his responses.

\section{Goose Set}

No. of

1. Nothing much.

2. ", ,

3. ", ,

4. Sheep.

5. They're all much about the same.

6. Still a sheep.

7. An elephant.

The same tendency is occasionally produced by a course of treatment when conscious memory of the set seen before is obliterated during the course of treatment.

A female patient was shown the goose set before beginning a course of treatment, and again a fortnight $\frac{D}{D}$ later after four treatments of E.C.T. The following is a comparison of her responses. She strenuously denied at $\overrightarrow{0}$ the second presentation having seen any of the pictures before.

No. of

Picture First Response

Goose Set

1. Nothing.

3. A different shape.

4. Same shape as before except at the top.

5. Slightly different again. What do you mean an animal? It's like a leaf or a leg of mutton.

6. No response.

7. More like $a$ duck.

\section{Second Response}

Looks like a pear.

A bit different now.

Don't know.

Leg of mutton.

Don't know.

Now we're coming : N it looks like-a o drake. 


\section{Discussion}

The difference in the points of recognition of familiar and unfamiliar sets of pictures seen during the post-E.C.T. amnesic state indicates quite clearly that if a set of pictures is seen before treatment it is more easily recognized after it than a new set seen at this time, even though the familiar set may be neither recalled nor recognized by the patient at the time when the responses are given. This finding seems to be important in drawing attention to two points :

1. Responses after E.C.T. are facilitated by their previous performance even when this performance is not consciously remembered. A similar facilitation of behaviour performance was found by Gregor and Roemer (1906) to result from practice in Korsakoff patients who yet retained no recollection of the learning period.

2. E.C.T. does not obliterate this facilitation even in very recent experiences, although it was not possible from the small number of cases tested in this experiment to ascertain the exact relationship between recency and facilitation.

From the results of the experiment it is furthermore apparent that a response made during the post-E.C.T. confusional period may also be facilitated by its previous enaction during this period, despite absence of recall and recognition of the event by the patient. It thus appears that facilitation of a response can be brought about, even when no memory of the response appears to be retained, although the facilitation induced in such cases does not extend into the post-confusional period.

Although these findings point to the conclusion that a preliminary viewing of a set of pictures aids its recognition in the confusional period, a comparison of the examples of individual responses quoted suggests that what appears to be recognition of the object may, in fact, only be a pattern of verbalization given in response to a visual and auditory stimulus, and that it is not so much conscious recognition of the object that is facilitated by previous stimulation, as a repetition of this response. On the other hand, it may be that conscious recognition of an object or event is concerned with the reawakening of perceptual patterns whose performance has been facilitated by previous excitation, and that this facilitation affects not only the one isolated response but also those in psychological proximity to it.

Further experiments are being made in an attempt to clarify this point.

\section{Summary}

The responses made by subjects in a post-E.C.T. amnesic state to unstructured material was investigated by means of three sets of pictures. Each set started off as a spherical ink blot, and developed through nine stages into a silhouette study of a familiar animal.

It was discovered that despite lack of recall and recognition on the part of the subjects, sets of pictures which had been shown to them either before the beginning of treatment, or in the early confusional period, were more easily recognized during the later confusional period than the other sets.

These findings are discussed in the light of some of the qualitative aspects of the responses.

I should like to acknowledge my gratitude to Dr. Joshua Carse, Medical Superintendent of Graylingwell Hospital, where these investigations have been carried out, and to Dr. M. B. Brody, Director of Clinical Research, for much helpful criticism and advice.

\section{REFERENCES}

Bartlett, F. C. (1932). " "Remembering": Cambridge. Bonhoeffer, K. (1901). " Die akuten Geisteskrenkeiten der Gewohnheitstrinker ". Jena.

Bumke, O. (1928). "Handbuch des Geisteskrankeiten". Berlin.

Bürger-Prinz, H., and Kaila, M. (1930). Z. ges. Neurol. Psychiat., 124, 553.

Gregor, A., and Roemer, H. (1906). Neurol. Zbl., 25, 339.

Kalinowsky, L. B., and Hoch, P. H. (1946). " "Shock Treatment". London.

Liberson, W. T., and Wilcox, P. H. (1945). Dig. Neurol. Psychiat., 13, 292.

Löwenbach, H., and Stainbrook, E. J. (1942). Amer. J. Psychiat., 98, 828.

MacCurdy, J. T. (1928). "Common Principles of Psychology and Physiology". Cambridge.

Mayer-Gross, W. (1943). Lancet, 2, 603.

Stone, Calvin, P. (1947a). J. abnorm. soc. Psychol., 42, 206.

(1947b). J. comp. Physiol. Psychol., 40, 183.

Wittman, M. P., and Russell, J. T. (1942). J. gen. Psychol., 26, 3.

Zubin, J., and Barrera, S. Eugene (1941). Proc. Soc. exp. Biol., N.Y., 48, 596. 